\title{
Erratum to: Outcomes and risk factors for unplanned delivery at home and before arrival to the hospital
}

Zlatko Lazić, Iztok Takaĉ

Erratum to: Wien Klin Wochenschr DOI 10.1007/s00508-010-1505-Z

Unfortunately the part „Ergebnisse“ in the german summary was printed erroneously and should read:

Ergebnisse: Von den 17.846 Geburten handelte es sich bei 58 (3,2\%o) um Geburten, die ungeplant zu Hause beziehungsweise am Weg ins Spital stattfanden. Der Vergleich der Sicherheit mit den Geburten im Spital ergab, dass diese ungefähr 7 mal sicherer sind als die ungeplanten Geburten zu Hause. Dies ergibt sich durch den Vergleich der perinatalen Mortalität, die bei den ungeplanten Geburten zu Hause $68 \%$ im Vergleich zu 8,8 \%o bei den Geburten im Spital betrug. 